\title{
The Expression and Research of Folk Culture in Book Binding Design
}

\section{--Taking Gannan Hakka Culture as an Example}

\author{
Jingying Wei ${ }^{1}$, a, Yong Tan ${ }^{2}$ \\ 1. School of Art and Design, Guangdong University of Science and Technology, Dongguan, \\ Guangdong 532000, China \\ 2. Institute of Marxism, Guangdong Food and Drug Vocational College, Guangzhou, Guangdong, \\ 510000, China \\ a275092195@qq.com
}

\begin{abstract}
Nowadays, with the rapid development of China, Folk culture turned to be ignored due the openness and progressive. Folk culture needs to be inherited as well as developed. So, we need to pay more attention to folk culture. Meanwhile, book binding design is inseparable from culture. This dissertation studies how to design books better and how to publicize Gannan Hakka culture which belongs to Folk culture better through books. This article revolves around Gannan Hakka culture under the folk culture, to get in further logically and discover the method of how to design the book which could be able to represent the feature of Gannan Hakka Cultuer hierarchically. Firstly, this dissertation introduces the present situation of book binding design and the importance of folk culture to the design of book binding. Secondly, we can take some examples about the behavior to the book binding design in folk culture from three elements in visual communication design graphic, text and color. And then drawing a conclusion with the design principles and performance techniques in the design of the book binding, besides illustrating the specific performance of Gannan Hakka by diet, customs, clothing, architecture. Finally, I finish the "Gannan Hakka culture," this book is the final research results of my book binding design used in Gannan Hakka culture.
\end{abstract}

Keywords: Book Binding Design; Folk Culture; Gannan Hakka Culture.

\section{Introduction}

This article mainly designs books to promote folk culture. Since the author is a native of Gannan, with a passion for his hometown, I conduct research from the Gannan Hakka culture in the folk culture.as multi-leveled equations, graphics, and tables are not prescribed, although the various table text styles are provided. The formatter will need to create these components, incorporating the applicable criteria that follow.

The Hakka is a ethnic group of the Han nationality in China. It is widely distributed and originated in the Central Plains. However, due to wars and other reasons, the Hakkas have experienced about six migrations to southern Jiangxi, Guangdong, and Fujian. The Hakka inherited the culture of the Central Plains and at the same time integrated the culture of the Central Plains with the residents and the culture of the mountain peoples, and finally evolved into the Hakka culture as we know it today. The Gannan area was the first area that Hakkas arrived from the south of the Central Plains, so the Gannan area is the birthplace of Hakka. Compared with the Hakka culture in Fujian and Guangdong, the Hakka culture in Gannan has developed relatively late, but in recent years, "Hakka" has been a hot topic in Jiangxi. The area of Gannan Hakka culture is mainly concentrated in Ganzhou area. Ganzhou is the southernmost city in Jiangxi Province and the second largest city in Jiangxi Province. Ganzhou has a long history, so its integrated culture is also more complex, covering Songcheng culture, Hakka culture and other cultures. Here in Ganzhou, there are clouds and mountains, beautiful bells, beautiful and rich in the south of the Yangtze River, unique enclosed houses, and simple folk customs; it has the reputation of being the red old capital and the cradle of Hakka. I set out to conduct on-the-spot investigations in Ganzhou and the county towns and villages of Ganzhou. Walk into the enclosed house, return to the countryside, and find the nostalgic memories in the hearts of the Hakka 
folks, to extract the design elements of this culture and use the design to convey the Gannan Hakka culture.

This book binding design is designed for a book that conveys Gannan Hakka culture. The content of the book is divided into four chapters: Hakka architecture, Hakka food, Hakka customs, and Hakka clothing. These four chapters explain Gannan. Hakka culture. The first chapter is the typical representatives of large and small "enclosed houses" in Hakka architecture, the ancient Hakka villages in Ruijin, to express the architectural cultural characteristics of Hakka in Gannan; Chapter Two, the food through the Hakka cuisine in southern Gannan, "Nan'an Banya", "Hot skin", "Pocket bag", etc. express the food culture of Hakka in Gannan; Chapter 3, Hakka customs are celebrated through Hakka festivals: such as Lantern Festival and Spring Festival, "Tie Dingjiao", "Bridge tied lights", " "Nuo Opera", "Dingnan Ruishi", "Red Ding Cocktail Party" and other annual custom activities, to show the Hakka people's prosperity and the symbolic meaning of a better life. The Hakka customs chapter also includes the Hakka cultured sentiment "Gannan" "Tea picking play" and "Blowing Suona" show the colorful and unique life of Hakka people in southern Gansu. There are also "Taoist sacrificial activities" and other customs that express Hakka customs and culture; Chapter 4, "Red straps" and " The Hakka child wearing a flower hat" to express love, expressing the Hakka feelings of the Hakka people in Gannan who are the great ancestor of the Hakka people. In terms of design, the ancients respected the old and liked to write vertically, so they chose to read the book from right to left, and the text was arranged in a vertical mode to read from top to bottom. There are many ways of binding and designing ancient books, and I choose the method of thread binding. Thread binding is a sign that the form of ancient book binding design has matured. Compared with the form of the previous books, the thread binding is more beautiful and practical, and the inner pages are less likely to be scattered. The book binding design also strives to achieve a combination of tradition and modernity. In the design of the inner page, the traditional elements of Gannan Hakka culture are extracted from the photographic materials taken by photography, and their own creativity is added to give them new life, achieving the fusion of folk culture and modern design. In the early stage of the design, the prerequisite is to take pictures and record pictures and interview the locals to understand the Hakka culture of Gannan by going deep into the countryside to experience the folk culture. The design is through the consideration, creation and redesign of the text, graphics, colors and materials of the book; Pay attention to the overall layout design of the layout, and use pictures and texts to promote Gannan Hakka culture and Gannan Hakka culture.

\section{The Value of Research Topics}

Gannan Hakka culture has practical cases in the research of native product packaging design and clothing design, but it has not studied Gannan Hakka culture through book binding design, so I choose books as a carrier to design. This is the innovation of this article. point.

The aesthetics of books is the aesthetic value, the readability of books is the practical value, and the integrity of the design should be paid attention to when designing this book. From the study of aesthetic value, a book with novel and unique design and exquisite printing technology can not only play the most basic role of disseminating culture and publicity, but also bring beautiful enjoyment to the viewer and bring a new visual experience. From the study of practical value, books have reading functions, and even more classic books have appreciative value and collection value. In the book binding design, the integration of Gannan Hakka culture and modern design, the integration of traditional design methods and modern design elements, aims to achieve overall unity in design and more intuitively show the unique nationality of Gannan Hakka culture. At the same time Without losing the design sense of the current design trend. In the end, it can show the reading, practical and aesthetic value of books, and achieve better attract readers to pay attention to Gannan Hakka culture, and then pay attention to folk culture, which can play a role in reading and promoting Hakka culture. 


\section{The Expression of Folk Culture in Book Binding Design}

Folklore culture is shown in the book binding design: Chapter 42 of Laozi's "Tao Te Ching" says that "one life is two, two is three, three is all things.", Three are faces and four are bodies. These are all tangible visual elements. The size and shape of points, lines and planes are different, and the emotions to be expressed are also different. The three elements of visual communication design are graphics, text, and color. From these three aspects, I will give examples and analyze the performance of folk culture in book binding design. Keep your text and graphic files separate until after the text has been formatted and styled. Do not use hard tabs, and limit use of hard returns to only one return at the end of a paragraph. Do not add any kind of pagination anywhere in the paper. Do not number text heads-the template will do that for you.

Examples of the performance of graphics in book binding design: graphics refer to spatial shapes in two-dimensional space. Compared with the two major elements of text and color, graphics are the most intuitive. Graphics can be seen everywhere in our lives, but the graphics mentioned in the design are different from the graphics in life. It is the designer who combines the design concept with his own creativity and ideas to express with graphics. The graphics in the design have more connotations than the graphics in life, because the designer re-emerges the graphics with life. Graphics are important in any design. The designer uses graphical language to make the viewer have a different visual experience, and convey the design content and theme ideas to the viewer through the form. The performance of graphics in folk culture can be through photography, taking some photos to perform some post-processing on the photos, or recreating and designing some characteristic folk auspicious symbols and traditional patterns. These traditional patterns have specific meanings and have been passed down to this day, carrying the spiritual connotation of culture, and having emotions beyond the artistic image.

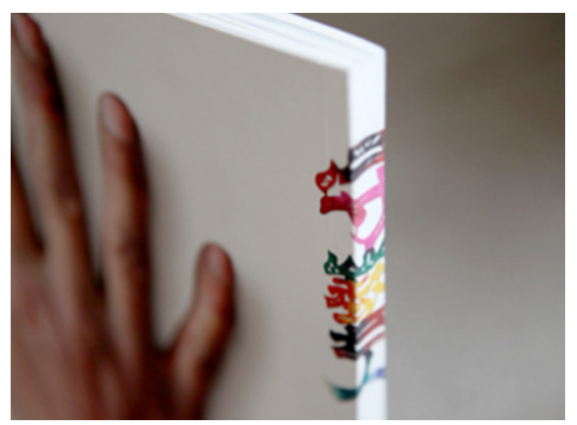

Figure 1. The cover design

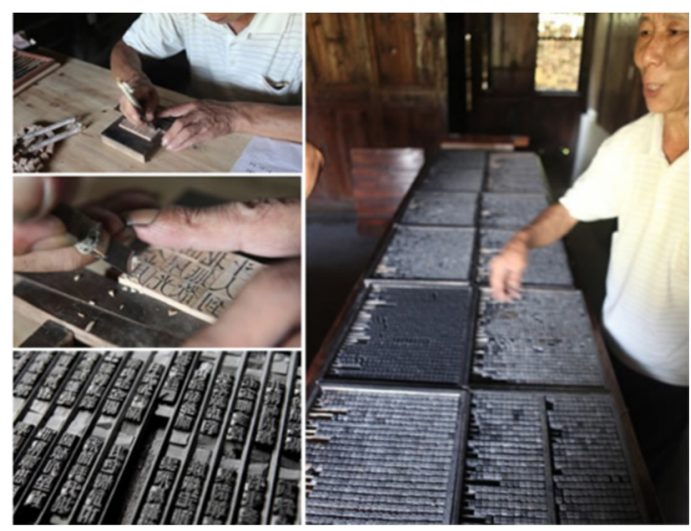

Figure 2. Mr. Cai Shiwei's design process display Image source: http://zj.zjol.com.cn/news/23069.html (2017)

For example, Taiwanese designer Mr. Cai Shiwei's "Shou Artist", this book takes the old papercutting artist Zhao Quan as the protagonist, including an introduction to the unique Yuxian paper- 
cutting tools, detailed process records and works, etc. The life of Master Zhao Quan; his family has been living in a cold and cold family for many years, relying on paper-cutting to support his family and his children to school. These hand-carved and dyed paper-cuts are different from mechanically produced works. They are devoted to the efforts of old artists. "Shou Artists" hopes to do its best to sell 150 sets of paper-cut works with 14 themes. Mr. Cai Shiwei used photographic techniques when designing "Shou Artist", and processed photos and graphics, such as the cover design (Figure 1, Figure 2).

Examples of expressions of text in book binding design: text is the main carrier in book binding design, conveying the main form of expression of book content. The choice of text layout and font style is one of the important factors of the beauty of book binding design, which can improve the reading speed of book content and highlight the theme content to be expressed, which has the finishing touch effect.

In the book binding design text performance, emphasizing the use of Chinese fonts, and recreating the fonts through the expression of calligraphy or seals combined with characteristic graphics. (Figure 3, Figure 4) For example: the third volume of a series of books "Goodbye Tradition" written by Mr. Lu Shengzhong. "Reappearing Tradition" III is a book that introduces folk culture. This book presents a kind of folk art of kneading soil and dough making people, and introduces handicrafts and folk artists and the stories behind them. The words "goodbye" and "tradition" on the cover and back cover design of this book all draw on the artistic expression of the seal, and the overall style is consistent with each other. Chinese culture has the characteristics of elegance. The combination of Chinese characters and calligraphy, and the redesign of the seal can better express the spirit of the cultural connotation and reflect the characteristics of elegance. The enlarged design of the words "Goodbye" and "Traditional" on the cover of "Reappearing Tradition" are all created by combining with graphics. The graphics presented on this font are all folk art described in the book content. The two words "Goodbye" on the cover of the book and "Traditional" on the back cover are combined with the content of the book to be conveyed, "Pinch Face Man" and integrated into the font design. The text here is both a text and a symbolic language. It not only has the function of conveying information, but also has the effect of decoration. Teacher Lu Shengzhong uses this method to let readers know the core cultural content of this book as soon as they look at the cover, and it also expresses the characteristic Chinese style very uniquely. Teacher Lu Shengzhong uses books as a medium to convey Chinese folk culture. This kind of specializing in folk culture and enthusiasm for book binding design is worthy of our reference and learning.

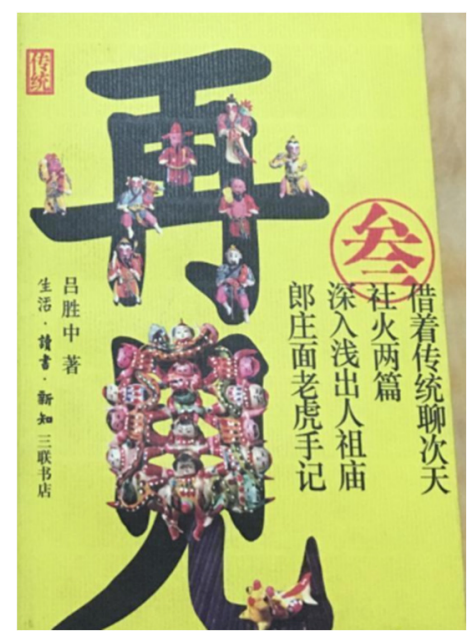

Figure 3. "Goodbye Tradition" Three Cover Design 


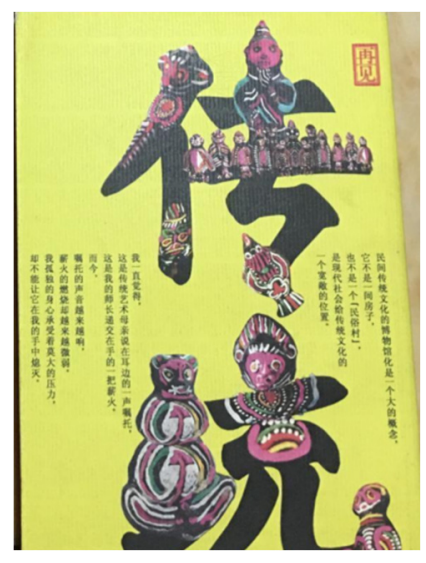

Figure 4. "Goodbye Tradition" Three Back Cover Design

\section{Design Theme}

The theme meaning of the book "Kannan Hakka Culture": This book is divided into four chapters, Hakka architecture, Hakka food, Hakka customs, Hakka clothing, and the representative Hakka cultural symbol of Gannan Hakka as its carrier-"Waiwu", "Lahuo", "Tian Ding Pao", "Dragon Dance and Lion", "Hakka Children's Flower Hat", etc., with red as the main line, and white as the echo to connect the whole book in series, thus forming the "Gannan Hakka Culture". Create books. Chapter One Hakka Architecture, Enclosed Houses, and Ancient Villages show the crystallization of Gannan Hakka architectural culture; Chapter Two Hakka food, wax goods, brown sugar, and purse, show the Hakka food culture in Gannan; Chapter Three Hakka customs, add Ding Pao and Rui Lions, Red Ding Cocktail Party, Nuo Opera, Sacrificial Ceremony, Bridge Tied Lanterns, etc. express the folk custom characteristics of Gannan; Chapter 4 Hakka costumes, red straps, and children's flower hats express Hakka sentiment, which together constitute the theme of "Hakka", thus extending Gannan The "Hakka affection" of the great ancestor of the South Hakka people has further sublimated the design theme.

Production form: A comprehensive three-dimensional display of Hakka local customs, lifestyles, etc., and the promotion of Gannan Hakka culture through this book binding design, conveying Gannan Hakka culture. The size and format of book binding design: $210 \mathrm{~mm} \times 297 \mathrm{~mm}$, book design form: thread binding has developed relatively mature in ancient book binding design in my country. Therefore, the method of thread binding was chosen to bind the book binding design. This book binding design uses Chinese style stitching, six-eye binding method, first punching, then threading. Scrolling form: scrolling from right to left. When designing the text, the layout is vertical, reading from top to bottom and from right to left. Book materials: The selected printing paper is: 1 . The letter is covered with 300 grams of white super-sensitive paper, which reflects the elegant and visually comfortable feeling; 2 . The cover and back cover use 240 grams of pure white paper, environmentally friendly art paper, The thick material is light, and the paper has a smooth surface texture when printing; 3. The 128 grams of white herbal paper used for the inner pages is a textured paper that can highlight the texture. Production process: 1 . Letter sleeves should be cut obliquely, 2. Hakka designs should be hot stamped or silver hot design, 3. Inside page design photos can be pasted together to turn the page. Design concept: This design serves as a cultural propaganda. Go deep into the countryside to visit around, photograph the different humanities and customs of the Hakka people in Gannan area, and complete the design by extracting the humanistic characteristics of the Hakka people in Gannan to promote the form and humanistic characteristics of the book binding design. Let the traditional customs of Gannan Hakka spread out, let the public know more about the Gannan Hakka system is a simple, natural, harmonious ecology, and a big family full of love. Let more people know the hard work, honesty and kindness of the Gannan Hakkas, and awaken the love in everyone's hearts. I hope that through this design, more people can know Gannan Hakka culture, understand Gannan Hakka culture, enter Gannan Hakka, spread the love of Hakka to every household, and disperse the affection 
of Hakka to everyone. What is more important is to preserve the long history of the Hakka culture in Gannan, which has been passed on from generation to generation.

Design style: The design style is a combination of traditional culture and modern design. For example, the use of modern photography methods combined with traditional culture, the same design from different angles and using a variety of color expressions to show the typical characteristics of Gannan Hakka culture, as well as people's lifestyles and so on. Using the combination of color blocks and text to highlight the theme of the photo, it is refreshing, expresses the theme clearly and clearly, and introduces the Gannan Hakka culture. The color is mainly red and white. Red has three meanings: 1. Red is an orthodox color of China since ancient times, which means Chinese red; 2 . Red represents Hakka red in Gannan Hakka; 3. Gannan is an old revolutionary base area, which means revolutionary red. The text is a supplementary introduction to the picture and the content of Gannan Hakka culture, which gives the picture a finishing touch. Increase the viewing and interest of the whole book. Design performance: From the perspective of performance, the most authentic side of Gannan Hakka people and the most authentic side of Gannan Hakka culture are shown in the shooting. Look for Hakka enclosures with typical architectural styles from the daily life of Hakkas in Gannan: Longnan Wushiwei, Longguangwei, Guanxiwei, Dongshengwei in Anyuan, Riyuewei Hakka enclosure in Xunwu Panoramic view, and historic Ruijin Mixi ancient villages, etc. The Hakka living habits, traditional festivals and traditional folk activities in Gannan will let readers understand and experience Hakka more intuitively. In terms of expressive techniques: 1. Extract traditional elements from culture to visualize it; 2 . Transform abstract graphics to convey the connotation of culture; 3 . Match text and graphics to highlight the overall effect. 4. In terms of color, the main color is red and white. The meaning of red: Red is an orthodox color in China. In Hakka, red has the meaning of continuation of maternal love and inheritance, and southern Jiangxi is the red base of the old revolution, so red is chosen as the main color. 5. Create an artistic conception through simple and comfortable typesetting, and give auspicious meaning to the combined design of text and graphics. The simple introduction of the overall design highlights the objectivity of the pictures and allows readers to see the pictures more intuitively.

The book is designed to be read from right to left, and the ancient Chinese reading habit is chosen to read this book from top to bottom. Use the combination of pictures and texts to show the truest side of Hakka, so that readers can understand Hakka culture in Gannan, feel Hakka culture in Gannan, and fall in love with Hakka culture in Gannan. Photography is the art of capturing the moment of beauty. This design achieves the visualization of graphics by refining the characteristic elements of Gannan Hakka culture, using smooth lines, concise color blocks, retro materials, harmonious pictures and beautiful text typography, combined into a creative and can Readable and enjoyable book binding design that introduces Gannan Hakka culture. The local customs and lifestyles of Gannan Hakka are displayed in an all-round and three-dimensional manner, and the Gannan Hakka culture is expressed through the carrier of book binding design.

\section{Design Content}

Letter case and letter case spine design description (Figure 5): Through the design of the two fonts of "Hakka" in Gannan Hakka culture, the font form of traditional Chinese characters for "Hakka" in the Hanyi seal script has brought me a good design. Inspiration. Then I think of the shape and shape of the Hakka house in Gannan. I transformed the two characters Hakka and blended it with the squareness of the building. I created Hakka fonts of my own design, designed three types, and finally selected the three designs and put them in the letter case (Figure 6). Because the feeling of design three is more unified, it is the overall feeling of the square, and it is more recognizable. The main color of this design is red for the letter case, and the font is also gold. The combination of red and yellow conforms to the Chinese characteristics and highlights the theme. When designing the cover of the letter case, a bevel cut is adopted to make the letter case unique and reveal the cover design of the inner pages. The letter case protects the album and is also convenient for readers to read and store. 
In the design of the spine of the letter sleeve, it is decorated with square-circle graphics to highlight the font design of Gannan Hakka culture. Because this book is in a thread-bound format, the inner pages of the book do not have a spine, so the spine is added to the design of the letter case to make it easier for readers to find the book.

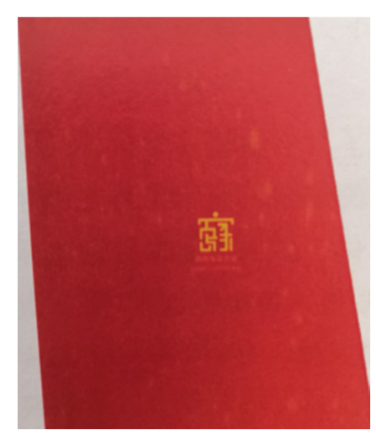

Figure 5. Letter sleeve design

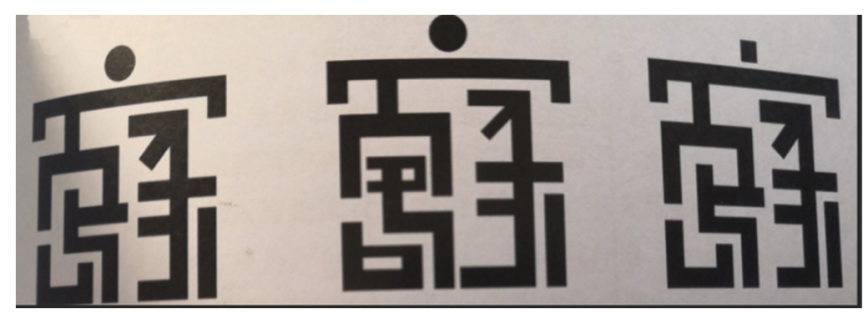

Figure 6. Hakka fonts designed by the author

Chapter General Description: Hakka mainly refers to the food and customs of the local people. The second chapter is about the characteristics of Hakka food culture. The main taste of Gannan is salty and spicy. The third chapter has the most content and is also the most important chapter of the whole book. It mainly introduces the Hakka customs of Gannan. There are Dragon Boat Festival, Mid-Autumn Festival, Spring Festival, Lantern Festival, and people's festivals will hold corresponding folk custom activities. During the Chinese New Year, there will be tin cannons, which symbolizes the prosperity of people and adds the meaning of males. The Hakka people have a difficult life due to many migrations, and they celebrate and value the inheritance of the clan. Of course, the Hakka tradition of patriarchalism that has been preserved for many years is deeply rooted. Timing means that during the Lantern Festival, all families in the village who have added a male child in the past year must gather to drink and set off firecrackers to celebrate. The lantern tied to the bridge is a unique folk dance Lantern Festival in southern Jiangxi. The bridge-tied lights are more than one hundred bridge benches, and the dragon's heads are connected to form a long bridge-tied lights. The beating of drums is deafening, the sound of suona, firecrackers and colorful fireworks in the sky, bridges with lights and dragons dancing up and down, walking on the streets, villagers pray for peace and prosperity, good weather, good health and prosperity. The bridge-tied lights radiated radiant light, reflecting the red sky and the earth, and the children and elders who played together were smiling, reflecting peace and prosperity. Designed in bright colors to highlight Hakka.

The overall design took several months. During the shooting on site, I felt a lot of moving, shock, and some regrets. At the same time, the page brought back many good memories of my growing up. In the pre-design preparation process, I re-understood the rich and colorful Gannan Hakka culture with a long history, and went deep into it to understand the characteristics of Gannan Hakka. After on-site visits and shooting, I was placed in the uniquely constructed Hakka enclosures and strolled through the quiet and long old alleys. I was influenced by the Hakka cultural heritage of these buildings, and deeply experienced the thickness and profoundness of the Hakka culture. When designing the book layout this time, I also admired the cases of many masters in the design world, 
how to create a freehand style, how to extract traditional elements for concrete transformation, etc., and to typeset and design the book with my own feelings. . While designing my page, I felt the allure of Gannan cuisine, and re-acquainted Hakka mothers with red straps. In my mind, they are more tenacious and committed, besides being simple. In this design, many folklore activities are festive and lively, and those festive scenes have profound meanings and people's wishes behind them. The design uses red as the main color to run through the four chapters, highlighting the Hakka culture in Gannan and expressing my deep "red" passion for Hakka. Through this design, the folk culture and Hakka culture in Gannan can be used as a research point. Continue to study in depth, but my life's energy can be exhausted. This design also gave me a deeper, comprehensive and new understanding and understanding of Gannan Hakka culture, and made me deeply feel the pride and pride of being a Gannan Hakka with Hakka blood. I am more deeply Love this red land in southern Jiangxi. No matter where you go, you will love this Hakka red and this deep Hakka love.

The design and style of the whole book are based on the Gannan Hakka culture, expressing the deep Hakka feelings of the Hakka people. In the early stage of the design, a large amount of literature was searched to understand the connotation of the rich Hakka culture in Gannan, and to determine the representative Hakka cultural symbols: fenced house, wax goods, tea picking play, dinging cannons, bridge tied lights, auspicious lions, children Hakka flower hats, red straps, etc., afterwards, deeply analyze and excavate each determined symbol, and understand the cultural connotation and foundation that they embodied. For example, for the red strap, go to Hakka to find the old folks wearing the red strap, choose the shooting angle, and record the most authentic, simple, and most lifelike aspect. The final design product display (as shown in Figure 7).
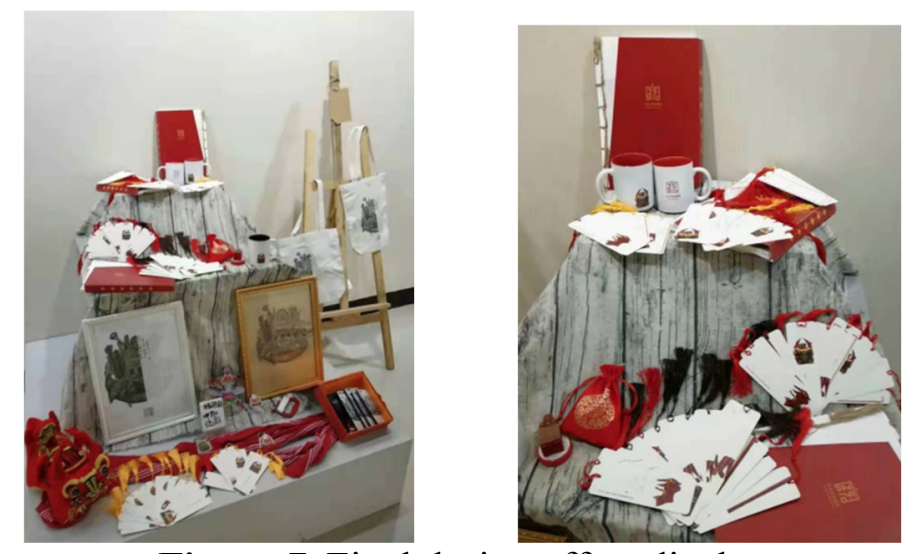

Figure 7. Final design effect display

\section{Summary and Outlook}

Gannan Hakka culture has examples in clothing design and packaging design, but it has not promoted Gannan Hakka culture through book binding design. This article hopes that this book binding design can better promote the Gannan Hakka culture, and even achieve more folk culture to get the public's attention.

Hakka culture is all-encompassing. Due to the limited space and personal level, this article only elaborates Gannan Hakka culture through four aspects: Gannan Hakka architecture, Gannan Hakka food culture, Gannan Hakka customs and culture, and Gannan Hakka costume culture. The uniquely constructed Hakka enclosed house-simple and heavy; dried duck, sausage, fried poached, emi fruit, Lei Cha-delicious and rich in cultural heritage; Nuo opera, sacrifice stove for keeping the year old, dragon and lion dance, dragon lantern tour-mysterious, Simple and lively. Lion head flower hat and red strap-beautiful, practical and profound. In the process of creation, I have spent a lot of effort on these aspects. I feel that I can only touch the tip of the iceberg of Gannan Hakka culture. The content is too much and the meaning is too deep. 
On the other hand, how to use book binding design, how to organically combine graphics, text, and colors, how to extract traditional elements from Gannan Hakka culture and express them concretely or use abstract design forms such as lines combined by text to express the Hakka taste, to express the Gannan Hakka culture, to give the meaning of the graphics, to create an artistic conception, which often feels powerless, and is often excited to catch a trace of inspiration. Sometimes I can't sleep at night....

In the final book of Gannan Hakka culture, I will be able to record the beautiful things of Hakka, and retain the most essential and essence of Gannan Hakka culture as much as possible. I hope that I can do my meager efforts to make folk culture. The background is more brilliant. At the same time, through the design of books, everyone has a brand-new visual experience of Gannan Hakka culture, and derivative designs of peripheral products (such as posters, mobile phone cases, etc.)

Nowadays, with the impact of the Internet, paper-based books are gradually being replaced by ebooks, and book binding enhances the artistry of paper-based books and opens new ways for them. Book binding design has entered a brand-new stage, which requires continuous innovation and development, and a design path of its own, which is inseparable from culture. Refining and applying traditional cultural elements to book binding design is the current development trend of book binding design in China.

In a practical sense, book binding design is a visual communication design for disseminating cultural information, not only to arouse people's attention and understanding of culture, but also a kind of beautiful language, which reflects the local folk culture. This book binding design applies the elements of Gannan Hakka folk culture to the book binding design. It is based on a deep understanding of Gannan Hakka culture to take its "shape", extend its "meaning", convey its "god", and let folk customs Culture has been innovated and developed in book binding design, and with the unique persistence and influence of book binding design itself, it can play a more extensive and communicative role. Faced with the trend of global design, as a designer, while constantly being impacted by foreign cultural design ideas, he must learn to combine Chinese and Western. Not only must keep up with the pace of the times, but also not forget the local culture, which is reflected in the book decoration design. Folk culture creates new design forms on the basis of absorbing reference. While pursuing innovation, it does not lose the embodiment of traditional styles, making the inheritance of culture more vigorous and modern, and achieving a true blend of folk culture and book binding design. . Judging from the economic development history of various economically developed countries, it is not too much to say that design is "economic benefit". Through the attention to book binding design and Gannan Hakka culture, the economic development of Ganzhou will be improved, the tourism development of Ganzhou will be promoted, and Gannan Hakka culture will be promoted.

From a social point of view, as the development of the world is becoming increasingly diversified today, China's book binding design should complement the unique folk culture elements in the international book binding design, so that the national book binding design culture can be innovatively developed. And out of the book binding design style with national characteristics, in the field of international packaging design, enhance the status of Chinese book binding design.

Hakka folk culture is rich and diverse. Folk culture has commonalities and historical stages; it also has social strata and ethnic diversity. The Hakka folk culture has a distinctive personality, various poses, and has an inexhaustible source of creation. The intimacy of traditional folk art is the result of direct contact and collision between people, people and things, and people and the world. It is simple yet vivid and touching. Therefore, the creators' understanding of the world, life, and society is integrated into every book binding design. It reproduces the lives, concepts and emotions of each generation and becomes the most direct source of art. Therefore, traditional folk culture is the most original art.

In the 21st century, China's book binding design will enter a new historical stage. Only in accordance with the development of social economy and the improvement of people's aesthetic needs, continuous innovation in book binding design will make it rich in culture. Only in this way, In order to make China's book binding design more developed. Only nationals belong to the world. For book 
binding design to embark on a national development path, it must be rooted in the traditional cultural soil, learn from traditional culture, and creatively transform the essence of traditional culture, so that traditional cultural elements in the book binding design have both national personality and It is epochal. Understand the relationship between Hakka folk culture and book binding design, so that it can be more widely used in book binding design. In the book binding design of economic globalization, seek for its own folk cultural elements and give full play to the influence of culture. The integration of tradition and modernity, the extraction and application of traditional cultural elements to book binding design works, creating diversified design trends, and creating brands are the development trends of domestic book binding design.

\section{References}

[1] Qiu Hengxing. Hakka people and Hakka culture. [M]. Commercial Press, 1998.

[2] Zhou Jianxin. Jiangxi Hakka. [M]. Guangxi Normal University Press. 2007.

[3] Lv Jingren. Calligraphy Questions. [M]. China Youth Publishing House. 2009.

[4] Lv Jingren. Lv Jingren book design. [M]. Hubei Fine Arts Publishing House. 2012.

[5] Lu Jingren. Book Design Foundation. [M]. Higher Education Press. 2012.

[6] Lu Jingren. Book Design Foundation. [M]. Higher Education Press. 2012.

[7] Hu Shouwen. Lu Jingren. Book Design. [M]. China Youth Publishing. 2014.

[8] Li Zehou. Three Books on Aesthetics. Hefei: Anhui Literature and Art Publishing House, 1999.

[9] Qian Weiqun. Jin Xiaoxiao. Book binding. [M]. Shanghai Jiaotong University Press. 2011.

[10] Yu Bingnan. Book Design. [M]. Hubei Fine Arts Publishing House. 2001.

[11] Zhu Yingchun. Design Poems. [M]. Guangxi Normal University Press. 2011.

[12] Zhu Yingchun. Insect Book. [M]. Guangxi Normal University Press. 2015. 